\title{
Professional values of nursing students in nursing leadership and management course
}

\author{
Mohammad Alboliteeh* \\ University of Hail, Hail city, Saudi Arabia
}

Received: October 23, 2018

Accepted: February 24, 2019

Online Published: February 28, 2019

DOI: $10.5430 / \mathrm{cns} . v 7 \mathrm{n} 2 \mathrm{p} 71$

URL: https://doi.org/10.5430/cns.v7n2p71

\begin{abstract}
Introduction: Determining the innate professional values of nursing students during their academic years in nursing schools provide a more concrete measurement of their professional readiness when they become licensed nurses. Background: Among all nursing subjects and courses, the Nursing Leadership and Management contains topics that emphasize professional adjustment and value development among students to become more professionally ready for the real world experience of the nursing profession. Objective: The study aimed to determine the perceived professional value orientation of the students to the five factors of Nurse Professional Values Scale-Revised. These factors are the values of Caring, Professionalism, Trust, Activism, and Justice.

Methodology: Using quantitative cross-sectional study design as the methodology, it included 200 nursing students both from the female and male campuses of a Saudi University. These 200 students as participants have finished the course Nursing Leadership and Management.

Results: The responses of the participants are mostly focused on the Caring factor where when ranked occupies the first top five (5) positions relating to the items $22,21,24,25,23$ with a mean of 3.49 ( $S D=1.19), 3.44(S D=1.28), 3.44(S D=1.24), 3.39$ ( $S D$ $=1.28), 3.37(S D=1.22)$, respectively. While the bottom five (5) of the responses pertains to the factors Professionalism (item 6), Caring (item 18), Professionalism (item 5), Trust (items 2 and 1). These factors received a mean of $3.9(S D=1.25), 3.17(S D=$ $1.35), 3.16(S D=1.15), 3.14(S D=1.22), 3.00(S D=1.39)$, respectively.

Conclusion: Caring being the essential element of the nursing profession is the most valued quality of nursing students. A full understanding of the essence of caring allows the future nurse professionals to deliver compassionate and sensitive nursing service.
\end{abstract}

Key Words: Nurse professional values, Leadership, Management nursing values, Nursing leadership, Nursing students professional values

\section{INTRODUCTION}

The dream of the holistically prepared nurse whose training has integrated proper moral values and intellectual competence has yet to come to fruition. Much has to be done, and a long road still lies ahead. ${ }^{[1]}$ The realization of the dream will happen within the nursing academe, where nurses are honed and prepared to become professionals. ${ }^{[2]}$ First, an assessment of the student's complex values about professionalism must be conducted (Price, 2012). Several organizations, such as the International Council of Nurses, have proposed measures and rubrics to determine these standards for nurse graduates. $^{[3]}$

*Correspondence: Mohammad Alboliteeh; Email: dr.alboliteeh1@gmail.com; Address: University of Hail, Hail city, Saudi Arabia. 
In their clinical experience provided through their internship program, nursing students are exposed to different situations involving patient care. One study in Indonesia examined the meanings of the lived experience of grief among Muslim nurses who worked in the critical care unit. The study's results revealed that the nurses' grieving attitudes in the process of providing care to patients impacted how they viewed the nursing profession. The loss of patients during the care process affected them emotionally, cognitively, spiritually, relationally, and professionally. ${ }^{[4]}$ In a different study by Aupia et al., ${ }^{[5]}$ they compared the differences in caring behaviors among nurses, patients, and nursing students and determined their relationships. Nursing students had the highest obtained score compared with the professional nurses and the patients after an 8-week clinical rotation in the hospital. The authors suggested that further studies should be conducted focusing on the topic of caring behaviors among nursing students to enhance their capabilities to provide care to patients.

The two previously mentioned studies suggest that the curricula of nursing colleges and universities should include subjects that enable students to understand the values of a nurse. Topics on ethics, morality, the legal system, and professional nursing values are taught and integrated into various nursing subjects. ${ }^{[6]}$ In courses on medical-surgical nursing, psychiatric nursing, pediatric nursing, among others, information on the legal and ethical duties of a nurse is presented in a particular unit or distributed in a group of various topics. However, one nursing subject in which the issues of professional nursing values and principles are fully covered and discussed is nursing leadership and management. ${ }^{[7]}$

Another study proved the shortages of nurses in some countries around the world. Even more importantly, studies have agreed that there is a shortage of advance and well-trained professional nurses. Several programs have been developed to address these issues, and leaders in nursing around the world are in constant collaboration trying to fill the gap and create solutions to these problems. ${ }^{[8]}$

Nelsey et al. argued that nursing employment should not be based solely on intellectual capacity and that there are other qualifications that must be met to ensure a safe culture of nursing care. A nurse's ethico-moral ideals, work ethics, attitudes toward authority, and professional and personal values systems are equally important in the assessment of his or her qualifications. ${ }^{[9]}$

\section{Background of the study}

Nursing organizations that represent the nursing workforce have the responsibility of providing the necessary assistance that includes, but is not limited to, sharing the skills required, teaching concepts to nurses that enable them to effectively carry out their duties, and orienting nurses toward the values of the profession. These efforts support nurses in gaining all the skills and competencies necessary to become responsible members of their healthcare team. To this effect, honing the professional values of student nurses while they are still in the academic environment will allow them more time and opportunity to acquire these values. ${ }^{[10]}$

Previously published research studies on professional nursing values primarily focused on healthcare provision, ethical care competencies, and care delivery systems and the ethicomoral obligations of nurses. There are no recent studies or studies published in the past ten years that explicitly discuss the professional value system of a nurse as influenced by his or her nursing education or the competencies and topics in nursing leadership and management that motivate, develop, and stimulate their professional value system. A study conducted by Kaya et al. showed that the social values of fourth-year nursing students were higher and much more appreciated compared with those in the lower year levels. Furthermore, the majority of the students' responses to the Nurses Professional Values Scale indicated that they considered human dignity to be the most crucial consideration in providing nursing care to patients. The students considered justice to be the second most significant value. ${ }^{[11]}$

Understanding the professional values of the students allows the healthcare system in Saudi Arabia to move in the direction of a compassionate healing environment. Saudi Arabia has a diverse nursing workforce, and understanding the professional values of nurses in the kingdom creates opportunities for more ethically responsive nursing care. ${ }^{[12]}$ The kingdom has come far in its quest for a healthcare system that is comparable to the leading healthcare systems around the world. Healthcare policies and laws are continuously being improved, and with this is the need to determine the professional values of nurses to become more prepared and responsible in the practice of the profession. ${ }^{[2]}$

In Saudi culture, providing care to a Saudi family member by a non-Saudi demands sensitivity of one's own culture and belief system. Conflicts may arise when a healthcare provider such as a nurse does not understand fundamental Islamic principles that should be considered while providing care. ${ }^{[13]}$

The objectives of this study were (1) to assess the characteristics of the students who were enrolled and had completed the Nursing Leadership and Management course, (2) to determine their responses on the Nurses Professional Values Scale-Revised (NPVS-R), (3) correlate the characteristics of the participants to their responses on the NPVS-R. 


\section{Methodology}

\subsection{Design and setting}

This study used a descriptive cross-sectional design. It was conducted at the University of Hail in Hail City, Saudi Arabia, at both the male and female campuses of the College of Nursing. During the period of data gathering, the number of students attending classes on the female campus of the College of Nursing was 310 students, whereas the number of students attending classes on the male nursing campus was 220. The University of Hail is the largest university in Hail Province under the Ministry of Education. The College of Nursing was founded in 2010, but the University has been in existence since 2005 .

\subsection{Participants}

A convenience sampling design was used to gather data through a self-report questionnaire from the students of the College of Nursing. The eligibility criteria were (1) bona fide student of the university enrolled during the second semester of academic year (AY) 2017-2018, (2) has completed the Nursing Leadership and Management course (whether passed or failed), and (3) completed the Nursing Leadership and Management course in any of the semesters from the first semester of AY 2016-2017 through the first semester of AY 2017-2018. Students who were still taking the course during the second semester of AY 2017-2018 were not included. A total of 200 students were included in the study. A total of 250 questionnaires were distributed, and 200 were returned completely answered (response rate $=$ $80 \%)$.

\subsection{Instrument}

Data were gathered using a two-part questionnaire in which the first part asked for characteristics of the participants and the second part asked for responses to the 26 Likert-like items of the NPVS-R. The first part of the instrument included questions on gender, English language fluency (e.g., not fluent, minimal), student status (e.g., regular, bridging), semester the Nursing Leadership and Management course was taken (e.g., first semester AY 2016-2017), and the grade obtained by the student (e.g., A+, A, F [failed]). The second part of the questionnaire determined the responses of the participants to the NPVS-R. The instrument was created by the American Nurses Association's Code of Ethics for Nurses. A previous version of the NPVS was published in 2000. Weis and Schank ${ }^{[14]}$ revised the scale to mirror the changing landscape of the nursing profession as reflected in the 2001 Code of Ethics for Nurses. Though there were originally eight factors measured by the NPVS, the NPVS-R measures five factors: caring, activism, trust, professionalism, and justice. Caring refers to the nurse's actions in providing welfare to patients; it is the central core of nursing practice. Justice is the foundation of a nurse's interactions across all healthcare settings. Professionalism refers to strict adherence to nursing standards in all healthcare settings. Trust involves maintaining one's competency in the profession. Activism defines the role of nurses in public affairs including policymaking roles and membership roles in nursing associations. ${ }^{[14]}$

The NPVS-R questionnaire consists of 26 items, which are divided into the five factors previously mentioned. Items 16 , $17,18,20,21,22,23,24$, and 25 are classified under factor 1 , which is caring; items $4,10,11,19$, and 26 are classified under factor 2, which is activism; items 1, 2, 9, 14, and 15 are classified under factor 3, which is trust; items $6,7,5$, and 8 are classified under factor 4 , which is professionalism; and lastly, items 3,12 , and 13 are classified under factor 5, which is justice. Responses are rated on a scale ranging from 1 ("not important") to 5 ("most important") with a possible range of scores between 26 and 130. The higher the derived score on the scale, the stronger the orientation toward professional values. ${ }^{[15]}$

\section{RESULTS}

Two hundred nursing students both from the male and female campuses of the College of Nursing at the University of Hail participated in this study. Out of the 200 participants, $82(41 \%)$ were male, and $118(59 \%)$ were female. About English fluency, 5 (2.5\%) students reported not being fluent, 67 (33.5\%) reported having minimal fluency, 108 (54\%) reported being moderately fluent, and 20 (10\%) reported having maximum fluency. About student status, 92 (46\%) were bridging students, whereas 107 (53.5\%) were regular students. In terms of the semester in which the Nursing Leadership and Management course was completed, the majority of students (64 [32\%]) completed the course in the second semester of AY 2016-2017, 55 (27.5\%) enrolled and completed the course during the first semester of AY 2016-2017, and $51(25.5 \%)$ and $30(15 \%)$ completed the course during the first semester AY 2017-2018 and second semester 20172018 , respectively. In terms of the grade obtained in the course, $72(36 \%)$ of the 200 students obtained either a $\mathrm{C}+$ or C, 53 (26.5\%) obtained either a B+ or B, 46 (23\%) obtained either a D+ or D, 18 (9\%) obtained either an A+ or A, and $11(5.5 \%)$ failed the course (see Table 1$)$.

The responses of the participants were mostly focused on the caring factor which, when ranked occupied the top five positions, which were for items $22,21,24,25$, and 23 with means of 3.49 (standard deviation $[S D]=1.19), 3.44(S D=$ $1.28), 3.44(S D=1.24), 3.39(S D=1.28)$, and $3.37(S D=$ 1.22 ), respectively (see Tables 2-4). While the bottom five responses pertained to professionalism (item 6), caring (item 
18), professionalism (item 5), and trust (items 1 and 2). For these factors, the means were $3.9(S D=1.25), 3.17(S D=$ $1.35), 3.16(S D=1.15), 3.14(S D=1.22)$, and $3.00(S D=$ 1.39), respectively (see Tables 2 and 4).

Items 22 ("Confront practitioners with questionable or inappropriate practice"), 21 ("Safeguard patient's right to privacy"), 24 ("Practice guided by principles of fidelity and respect for person"), 25 ("Maintain confidentiality of patient"), and 23 ("Protect rights of participants in research") were perceived as the most important professional values to be considered. All of these items were categorized under the factor of caring.

Table 3 shows the ranking for the five factors measured by the NPVS-R. Caring was ranked the highest of all the factors (mean $=3.37 ; S D=1.04$ ), followed by activism (mean $=3.28 ; S D=1.01)$, trust (mean $=3.21 ; S D=1.10)$, professionalism $($ mean $=3.21 ; S D=1.08)$, and justice (mean $=2.45 ; S D=0.82$ ), in that order. An analysis of variance was performed on the data to determine whether there were significant differences among the responses to the 26-item NPVS-R questionnaire when grouped according to the five factors measured by the scale (i.e., caring, trust, professionalism, activism, and justice). Gender, student status, fluency in the English language, semester the Nursing Leadership and Management course was taken, and the grade obtained by the participants were compared for the five factors.

Table 1. Demographic profile of the participants $(\mathrm{N}=200)$

\begin{tabular}{llll}
\hline Profile of the participants & $\boldsymbol{n}$ & \% \\
\hline \multirow{2}{*}{ Gender } & Male & $82(41)$ & 41 \\
& Female & $118(59)$ & 59 \\
& Not Fluent & $5(2.5)$ & 2.5 \\
English Fluency & Minimal & $67(33.5)$ & 33.5 \\
& Moderate & $108(54)$ & 54 \\
& Maximum & $20(10)$ & 10 \\
Student Status & Bridging & $92(46)$ & 46 \\
& Regular & $107(53.5)$ & 107 \\
\multirow{5}{*}{ Semester } & 1st Sem AY 2016-2017 & $55(27.5)$ & 27.5 \\
& 2nd Sem AY 2016-2017 & $64(32)$ & 32 \\
& 1st Sem AY 2017-2018 & $51(25.5)$ & 25.5 \\
& 2nd Sem AY 2017-2018 & $30(15)$ & 15 \\
Grade & A+ / A & $18(9)$ & 9 \\
& B+ / B & $53(26.5)$ & 26.5 \\
& C+ / C & $72(36)$ & 36 \\
& D+ / D & $46(23)$ & 23 \\
& F & $11(5.5)$ & 5.5 \\
\hline
\end{tabular}

Table 3 shows the responses of the participants on the NPVS$\mathrm{R}$ by their characteristics. About gender, it was revealed that all the factors except justice, when compared, showed a significant difference, but overall, there was a significant difference $(\mathrm{F}=9.876 ; p=.015)$. For student status, there was a significant difference whether the participant was classified as a bridging student or a regular student $(\mathrm{F}=0.706 ; p=$ $.000)$. For English language fluency, the results showed that there was a significant difference $(\mathrm{F}=2.762 ; p=.043)$. For the semester the course was taken and completed, there was a significant difference among the responses to the five factors measured by the scale $(\mathrm{F}=4.852 ; p=.003)$. Lastly, the grade obtained by the participants showed no significant difference $(\mathrm{F}=1.136 ; p=.341)$.

\section{Discussion}

This study assessed the characteristics of the students who were enrolled and had completed the Nursing Leadership and Management course. Secondly, it determined their responses on the Nurses Professional Values Scale-Revised or NPVSR and thirdly; it correlated the characteristics of the participants to their responses on the NPVS-R.

Nursing Leadership and Management course highlight the role of nurse managers in leading the nursing staff in a hospital. To fulfill this role, nurse managers should be equipped with the necessary skills, values, and competencies required of a leader. Only then can a nurse manager achieve professionalism and embody all the values required and expected of him or her. Most nursing colleges offer the course on nursing leadership and management in the last year of the nursing program. One reason could be that it for nursing students to be able to understand the more complicated concepts of the course, they must have completed all the core and even elective courses in the nursing program. ${ }^{[16]}$

The primary purpose of this study was to determine whether the characteristics of the participants correlated with their responses on the NPVS-R questionnaire. The characteristics that were used to determine the relationship of the responses in the scale were gender, student status, fluency in the English language, semester the Nursing Leadership and Management course was taken, and the grade obtained by the participants. One study, conducted in Korea, examined the professional values of nursing students, especially about self-esteem, interpersonal relationships, and self-efficacy, to identify factors that affected empathy in the care of patients. It was determined that self-esteem and self-efficacy were associated with diversified and individualized care. ${ }^{[17]}$ Tang et al. found caring to be undervalued in nursing practice. The development of nursing as a profession depends on how caring is emphasized because caring is the very core of the nursing profession. Nurses should show compassionate caring toward their patients in their daily practice. Caring should once again be considered an essential element of nursing, and nurses must be passionate about providing care to their patients. ${ }^{[18]}$ 
Table 2. The professional values indicators when they are ranked based on the responses of the participants $(\mathrm{N}=200)$

\begin{tabular}{|c|c|c|c|c|}
\hline Item number and Statement & Factor & Mean & Standard Deviation & Rank \\
\hline $\begin{array}{l}22 \text { "Confront practitioners with questionable or inappropriate } \\
\text { practice" }\end{array}$ & Caring & 3.49 & 1.190 & 1 \\
\hline 21 "Safeguard patient's right to privacy" & Caring & 3.44 & 1.282 & 2 \\
\hline 24 "Practice guided by principles of fidelity and respect for person” & Caring & 3.44 & 1.239 & 3 \\
\hline 25 “Maintain confidentiality of patient” & Caring & 3.39 & 1.279 & 4 \\
\hline 23 "Protect rights of participants in research" & Caring & 3.37 & 1.221 & 5 \\
\hline 20 “Provide care without prejudice to patients of varying lifestyles” & Caring & 3.36 & 1.244 & 6 \\
\hline 26 "Participate in activities of professional nursing associations" & Activism & 3.34 & 1.274 & 7 \\
\hline $\begin{array}{l}13 \text { "Assume responsibility for meeting health needs of the culturally } \\
\text { diverse population” }\end{array}$ & Justice & 3.33 & 1.207 & 8 \\
\hline 16 "Protect moral and legal rights of patients" & Caring & 3.33 & 1.182 & 9 \\
\hline $\begin{array}{l}17 \text { "Refuse to participate in care if in ethical opposition to own } \\
\text { professional values" }\end{array}$ & Caring & 3.32 & 1.239 & 10 \\
\hline 9 "Seek additional education to update knowledge and skills" & Trust & 3.32 & 1.230 & 11 \\
\hline 15 "Maintain competency in area of practice” & Trust & 3.32 & 1.242 & 12 \\
\hline $\begin{array}{l}19 \text { "Participate in nursing research and/or implement research } \\
\text { findings appropriate to practice" }\end{array}$ & Activism & 3.31 & 1.257 & 13 \\
\hline $\begin{array}{l}7 \text { "Promote and maintain standards where planned learning activities } \\
\text { for students take place" }\end{array}$ & Professionalism & 3.31 & 1.135 & 14 \\
\hline 14 "Accept responsibility and accountability for own practice" & Trust & 3.29 & 1.238 & 15 \\
\hline 12 "Promote equitable access to nursing and health care" & Justice & 3.28 & 1.249 & 16 \\
\hline $\begin{array}{l}4 \text { "Participate in public policy decisions affecting distribution of } \\
\text { resources" }\end{array}$ & Activism & 3.26 & 1.215 & 17 \\
\hline $\begin{array}{l}10 \text { "Advance the profession through active involvement in health } \\
\text { related activities" }\end{array}$ & Activism & 3.26 & 1.220 & 18 \\
\hline $\begin{array}{l}11 \text { "Recognize role of professional nursing associations in shaping } \\
\text { health care policy" }\end{array}$ & Activism & 3.25 & 1.230 & 19 \\
\hline 8 "Initiate actions to improve environments of practice" & Professionalism & 3.20 & 1.240 & 20 \\
\hline 3 "Protect health and safety of the public" & Justice & 3.19 & 1.242 & 21 \\
\hline 6 "Establish standards as a guide for practice" & Professionalism & 3.19 & 1.252 & 22 \\
\hline 18 "Act as a patient advocate" & Caring & 3.17 & 1.348 & 23 \\
\hline 5 "Participate in peer review" & Professionalism & 3.16 & 1.154 & 24 \\
\hline $\begin{array}{l}2 \text { "Request consultation/collaboration when unable to meet patient } \\
\text { needs" }\end{array}$ & Trust & 3.14 & 1.224 & 25 \\
\hline 1 "Engage in on-going self-evaluation" & Trust & 3.00 & 1.387 & 26 \\
\hline
\end{tabular}

Table 3. Professional values of participants when grouped according to the indicators $(\mathrm{N}=200)$

\begin{tabular}{llllll}
\hline \multirow{2}{*}{ Indicators } & \multirow{2}{*}{} & \multirow{2}{*}{ Mean } & Standard Deviation & \multicolumn{2}{c}{ 95\% confidence interval } \\
\cline { 5 - 6 } & & & & Lower Bound & Upper Bound \\
\hline Caring & 200 & 3.37 & 1.04 & 3.22 & 3.51 \\
Trust & 200 & 3.21 & 1.10 & 3.06 & 3.36 \\
Justice & 200 & 2.45 & 0.82 & 2.33 & 2.56 \\
Professionalism & 200 & 3.21 & 1.08 & 3.06 & 3.36 \\
Activism & 200 & 3.28 & 1.01 & 3.14 & 3.42 \\
Overall & 200 & 3.28 & 1.00 & 3.15 & 3.42 \\
\hline
\end{tabular}


Table 4. Participants' profile and their responses to the different factors of the NPVS-R $(N=200)$

\begin{tabular}{|c|c|c|c|c|c|}
\hline Participants' Profile & & Mean & F value & SD & Interpretation \\
\hline \multirow{2}{*}{ Gender } & Male & 82 & \multirow{2}{*}{9.876} & \multirow{2}{*}{0.015} & \multirow{2}{*}{ Significant difference } \\
\hline & Female & 118 & & & \\
\hline \multirow{2}{*}{ Student Status } & Bridging & 92 & \multirow{2}{*}{0.706} & \multirow{2}{*}{0.000} & \multirow{2}{*}{ Significant difference } \\
\hline & Regular & 108 & & & \\
\hline \multirow{4}{*}{$\begin{array}{l}\text { Fluency to the English } \\
\text { language }\end{array}$} & Not fluent & 5 & \multirow{4}{*}{2.762} & \multirow{4}{*}{0.043} & \multirow{4}{*}{ Significant difference } \\
\hline & Minimal & 67 & & & \\
\hline & Moderate & 108 & & & \\
\hline & Maximum & 20 & & & \\
\hline \multirow{4}{*}{$\begin{array}{l}\text { Semester the subject } \\
\text { was taken }\end{array}$} & 1st sem-AY 2016-2017 & 55 & \multirow{4}{*}{4.852} & \multirow{4}{*}{0.003} & \multirow{4}{*}{ Significant difference } \\
\hline & 2nd sem-AY 2016-2017 & 64 & & & \\
\hline & 1st sem-AY 2017-2018 & 51 & & & \\
\hline & 2nd sem-AY 2017-2018 & 30 & & & \\
\hline \multirow{5}{*}{ Grade } & $\mathrm{A}+/ \mathrm{A}$ & 18 & \multirow{5}{*}{1.136} & \multirow{5}{*}{0.341} & \multirow{5}{*}{ No Significant difference } \\
\hline & $\mathrm{B}+/ \mathrm{B}$ & 53 & & & \\
\hline & $\mathrm{C}+/ \mathrm{C}$ & 72 & & & \\
\hline & $\mathrm{D}+/ \mathrm{D}$ & 46 & & & \\
\hline & $\mathrm{F}$ & 11 & & & \\
\hline
\end{tabular}

Among the characteristics of the participants, gender showed a significant difference. This finding is supported by the study of Schmidt where the author investigated the core professional values of men in the nursing profession and found that their benefits are poorly understood by some. ${ }^{[19]}$ In contrast, a study conducted by Allari et al. on female nursing students in Saudi Arabia showed that females are more likely to be highly oriented toward their professional nursing values, especially on the issues of confidentiality, privacy of patients, moral and legal rights of patients, and the maintenance of a safe nursing environment in the hospital. ${ }^{[12]}$

Results revealed that most of the participants had a minimal to the moderate command of English. The use of language in the provision of nursing care as well as the nurse's understanding of professional values may have some impact on care provision. Language issues can derail the proper provision of nursing care; however, the utilization of professional interpretation standards in the clinical setting may help minimize this problem. ${ }^{[20]}$ The proficiency of the students in the use of the English language is a critical determinant in understanding not only Nursing Leadership and Management concepts but also other subjects or courses in the nursing program. ${ }^{[21]}$ Nursing being one of the healthcare professions requires the mastery of English as a language of communication among colleagues in the continuity of care. ${ }^{[22]}$

Grades obtained in a particular course may impact future performance. Thus, a standardized, fair, and accurate grad- ing system must be in place to fairly and accurately assess student competency. Diversity in the students' belief systems and value acquisition does not show a direct correlation with their performance in a nursing course; however, an assessment tool that is not well defined may cause serious concerns for both the educator and the student. ${ }^{[23]}$ For nurses to be able to make sound clinical judgments, they must first be oriented to the values of the profession. This will result in safe and ethically sound nursing care. ${ }^{[24]}$ For nursing students to develop the ability to make decisions based on the Code of Ethics for Nurses, the nursing curriculum should be designed with a greater emphasis on ethics, laws, and morals. Nursing schools must include ethical and moral standards in their curriculum to teach students how to separate their personal values from standard professional nursing values to make nonbiased nursing care decisions. ${ }^{[25]}$

The study design allowed the determination of the characteristics of those students who had completed the Nursing Leadership and Management course up to 1 academic year earlier and the students who had just completed the course. One advantage of this design is that it allows the data to be procured within a short period and can involve other sampling techniques. However, one possible limitation is that information cannot be ascertained on the conditions in which the data were collected and the behaviors of the participants during the data collection (e.g., whether their responses were compatible with other indicators or whether the responses came from other sources). 
Nursing schools provide the best opportunities for learning and developing professional values. Factors such as the learning experience of the student with the instructor, collaboration among classmates, and experiences during the clinical internship impact the nurses' adherence to standard professional values. ${ }^{[2]}$ An ethical climate in the hospital led by a moral leader yields a more efficient and positive work environment. Nurses, who make up the largest group of healthcare professionals in the hospital, can contribute to this ethical climate. ${ }^{[27]}$ One barrier to achieving the goal of making all nurses in the clinical setting aware of professional nursing values is when these values become nonapparent in their behaviors due to some factors. For this reason, hospital management must establish programs that further enhance the professionalism of nurses. ${ }^{[28]}$

\section{Conclusion}

Caring being the essential element of the nursing profession is the most valued quality of nursing students. A full understanding of the essence of caring allows future nurse professionals to deliver compassionate and sensitive nursing service. Studies that promote ethics and morality in nurs- ing provide perspectives that can make student nurses more aware of their professional obligations. When students grow in this awareness, patients who receive care from them are assured that they work within the bounds of patient safety culture and that they will receive respectful and dignified care. When nurses understand the issues related to ethical care provision, they became more aware and oriented to their responsibilities toward their patients. To ensure this is the case, nurse managers and leaders must take the initiative by becoming more visible and available when nurses need advice the most. Their presence is considered an affirmation of the importance of valuing ethical care and a reflection of ethical leadership.

The primary role of nursing instructors and professors is to deliver knowledge and orientation to their students on the importance of leadership roles. These roles will be better understood and will be realized when nurse graduates begin working as professional nurses, bringing with them what has been learned from nursing schools.

\section{CONFlicts of InTEREST Disclosure}

The author declares no conflicts of interest.

\section{REFERENCES}

[1] Sturgeon D. Transforming higher education and the professional preparation of nurses. Br J Nurs. 2010; 19(3): 180-184. PMid:20220662. https://doi.org/10.12968/bjon.2010.19. 3.46539

[2] Alghamdi MG, Urden LD. Transforming the nursing profession in Saudi Arabia. J Nurs Manag. 2016; 24(1): E95-E100. PMid:25808066. https://doi.org/10.1111/jonm. 12301

[3] Harmoinen M, Niiranen K, Niiranen V, et al. Stories of management in the future according to young adults and young nurses. Contemp Nurse. 2014; 47(1-2): 69-78. PMid:25267129. https: //doi.org/10.1080/10376178.2014.11081908

[4] Betriana F, Kongsuwan W. Lived experiences of grief of Muslim nurses caring for patients who died in an intensive care unit: A phenomenological study. Intensive Crit Care Nurs. 2018. PMid:30297149. https://doi.org/10.1016/j.iccn.2018.09 .003

[5] Aupia A, Lee TT, Liu CY, et al. Caring behavior perceived by nurses, patients and nursing students in Indonesia. J Prof Nurs. 2018; 34(4): 314-319. PMid:30055686. https://doi.org/10.1016/j.prof nurs.2017.11.013

[6] Elliott AM. Professional Values Competency Evaluation for Students Enrolled in a Concept-Based Curriculum. J Nurs Educ. 2017; 56(1): 12-21. PMid:28118470. https://doi.org/10.3928/01484834 $-20161219-04$

[7] Crisp C. Nursing Leadership. Tenn Nurse. 2016; 79(1): 10. PMid:27089563.

[8] Johnson JE, Billingsley M, Crichlow T, et al. Professional development for nurses: mentoring along the $\mathrm{u}$-shaped curve. Nurs Adm Q.
2011; 35(2): 119-125. PMid:21403485. https://doi.org/10.1 097/NAQ. 0b013e31820f69c0

[9] Nelsey L, Brownie S. Effective leadership, teamwork and mentoringessential elements in promoting generational cohesion in the nursing workforce and retaining nurses. Collegian. 2012; 19(4): 197-202. PMid:23362605. https://doi.org/10.1016/j. colegn. 2012. 03.002

[10] Weinstein AR, Dolce MC, Koster M, et al. Integration of systematic clinical interprofessional training in a student-faculty collaborative primary care practice. J Interprof Care. 2018; 32(1): 104-107. PMid:29111826. https://doi .org/10.1080/13561820.2017. 1355296

[11] Kaya H, Isik B, Senyuva E, et al. Personal and professional values held by baccalaureate nursing students. Nurs Ethics. 2017; 24(6): 716-731. PMid:26822298. https://doi.org/10.1177/096973 3015624488

[12] Allari RS, Ismaile S, Househ M. Professional Values Among Female Nursing Students in Saudi Arabia. Stud Health Technol Inform. 2017; 238: 231-234. PMid:28679931.

[13] Mutair AS, Plummer V, O'Brien AP, et al. Providing culturally congruent care for Saudi patients and their families. Contemp Nurse. 2014; 46(2): 254-258. PMid:24787260. https ://doi.org/10.5 172 /conu. 2014.46.2.254

[14] Weis D, Schank MJ. Development and psychometric evaluation of the Nurses Professional Values Scale-Revised. J Nurs Meas. 2009; 17(3): 221-231. PMid:20069950. https://doi .org/10.1891/10 $61-3749 \cdot 17 \cdot 3 \cdot 221$

[15] Weis D, Schank MJ. Development and Psychometric Evaluation of the Nurses Professional Values Scale-3. J Nurs Meas. 2017; 25(3): 
400-410. PMid:29268825. https ://doi.org/10.1891/1061-3 749.25 .3 .400

[16] Wei H, Roberts P, Strickler J, et al. Nurse leaders' strategies to foster nurse resilience. J Nurs Manag. 2018. https://doi .org/10.111 $1 /$ jonm. 12736

[17] Kim J. Factors influencing nursing students' empathy. Korean J Med Educ. 2018; 30(3): 229-236. PMid:30180510. https ://doi .org/ $10.3946 / \mathrm{kjme} .2018 .97$

[18] Tang FWK, Ling GCC, Lai ASF, et al. Four Es of caring in contemporary nursing: Exploring novice to experienced nurses. Nurs Health Sci. 2018. PMid:30156371. https ://doi.org/10.1111/nhs. 12 561

[19] Schmidt BJ. Core professional nursing values of baccalaureate nursing students who are men. Nurs Ethics. 2016; 23(6): 674-684. PMid:25899723. https://doi.org/10.1177/09697330155793 10

[20] Plaza Del Pino FJ, Soriano E, Higginbottom GM. Sociocultural and linguistic boundaries influencing intercultural communication between nurses and Moroccan patients in southern Spain: a focused ethnography. BMC Nurs. 2013; 12: 14. PMid:23705680. https ://doi.org/10.1186/1472-6955-12-14

[21] Kaliyadan F, Thalamkandathil N, Parupalli SR, et al. English language proficiency and academic performance: A study of a medical preparatory year program in Saudi Arabia. Avicenna J Med. 2015; 5(4): 140-144. PMid:26629471. https://doi.org/10.4103/22 31-0770.165126
[22] El Tantawi M, Al-Ansari A, Sadaf S, et al. Evaluating the English language scientific writing skills of Saudi dental students at entry level. East Mediterr Health J. 2016; 22(2): 148-153. PMid:27180743. https://doi.org/10.26719/2016.22.2.148

[23] O’Flynn-Magee K, Clauson M. Uncovering nurse educators' beliefs and values about grading academic papers: guidelines for best practices. J Nurs Educ. 2013; 52(9): 492-499. PMid:23952770. https://doi.org/10.3928/01484834-20130819-01

[24] Poorchangizi B, Farokhzadian J, Abbaszadeh A, et al. The importance of professional values from clinical nurses' perspective in hospitals of a medical university in Iran. BMC Med Ethics. 2017; 18(1): 20. PMid:28249603. https : //doi .org/10.1186/s12910 -017-0178-9

[25] Pickles D, de Lacey S, King L. Conflict between nursing student's personal beliefs and professional nursing values. Nurs Ethics. 2017 PMid:29153012. https://doi.org/10.1177/09697330177381 32

[26] Fernandez-Feito A, Palmeiro-Longo MD, Hoyuelos SB, et al. How work setting and job experience affect professional nurses' values. Nurs Ethics. 2017. PMid:28393606. https ://doi.org/10.1177/ 0969733017700238

[27] Barkhordari-Sharifabad M, Ashktorab T, Atashzadeh-Shoorideh F. Ethical leadership outcomes in nursing. Nurs Ethics. 2017. https : //doi.org/10.1177/0969733016687157

[28] Storaker A, Naden D, Saeteren B. Hindrances to achieve professional confidence: The nurse's participation in ethical decision-making. Nurs Ethics. 2017. https://doi.org/10.1177/096973301772 0827 